\title{
Universiteit
}

Leiden

The Netherlands

\section{Childrearing style of anxiety-disordered parents} Lindhout, I.; Markus, M.T.; Hoogendijk, T.; Borst, S.R.; Maingay, R.; Spinhoven, P.; ... ; Boer, F.

\section{Citation}

Lindhout, I., Markus, M. T., Hoogendijk, T., Borst, S. R., Maingay, R., Spinhoven, P., ... Boer, F. (2006). Childrearing style of anxietydisordered parents. Child Psychiatry And Human Development, 37, 89-102. doi:10.1007/s10578-006-0022-9

Version: $\quad$ Not Applicable (or Unknown)

License: $\quad$ Leiden University Non-exclusive license

Downloaded from: $\quad$ https://hdl.handle.net/1887/13189

Note: To cite this publication please use the final published version (if applicable). 


\title{
Childrearing Style of Anxiety-Disordered Parents
}

\author{
Ingeborg Lindhout • Monica Markus • \\ Thea Hoogendijk · Sophie Borst • \\ Ragna Maingay · Philip Spinhoven • \\ Richard van Dyck · Frits Boer
}

Published online: 8 June 2006

(C) Springer Science+Business Media, Inc. 2006

\begin{abstract}
This study investigated whether anxiety-disordered (AD) parents differ in their childrearing style from non-disordered parents. A clinical sample of $36 \mathrm{AD}$ parents with children aged 6-18 was compared with a normal control sample of 36 parents. Childrearing was assessed through parent report and child report. The results demonstrated significant differences in childrearing style between AD parents and non-disordered control parents, both from the perspective of the parent and from that of the child. AD parents reported a less nurturing and more restrictive rearing style than control parents. Their children did not report more rejection or less warmth than children of control parents; they did, however, report significantly more overprotection than children of control parents. The findings, from parental as well as child reports, apply to both $\mathrm{AD}$ mothers and $\mathrm{AD}$ fathers.
\end{abstract}

Keywords Parental anxiety disorders $\cdot$ Childrearing style $\cdot$ Parent report $\cdot$ Child report

\footnotetext{
I. Lindhout $(\bowtie) \cdot$ M. Markus $\cdot$ T. Hoogendijk $\cdot$ S. Borst $\cdot$ R. Maingay $\cdot$ F. Boer Academic Centre for Child and Adolescent Psychiatry Curium and Leiden University Medical Centre, Endegeesterstraatweg 27, 2342 AK Oegstgeest, The Netherlands e-mail: ilindhout@triversum.nl

P. Spinhoven

Department of Clinical Health Psychology, University of Leiden, P.O. Box 9555, 2300 RB Leiden, The Netherlands

R. van Dyck

Department of Psychiatry VU Medical Centre/GGZ BuitenAmstel, Free University, Valeriusplein 9, 1075 BG Amsterdam, The Netherlands

I. Lindhout

Triversum, Centre for Child and Adolescent Psychiatry, P.O. Box 225, 1800 AE Alkmaar,

The Netherlands

F. Boer

AMC-De Bascule, P.O. Box 12474, 1100 AL Amsterdam, The Netherlands
} 


\section{Introduction}

Anxiety disorders aggregate in families. Studies of the offspring of anxiety-disordered (AD) adults have demonstrated that these children are at high risk of becoming anxietydisordered themselves [1-4]. Likewise, parents and siblings of AD children show a higher prevalence of anxiety disorders than is found in general $[5,6]$ Behavioural-genetic research has demonstrated that heredity accounts for part of the familial transmission of anxiety disorders, but it has indicated a substantial environmental contribution as well [7-9].

One potentially mediating factor in the familial transmission of anxiety disorders is parental rearing style [10]. Clinical impressions of the contribution of childrearing style to the etiology of emotional disorders have been traced back as far as the seventeenth century $[11,12]$. There is a vast literature now on the potential role of childrearing in the development of anxiety. The majority of these studies have compared anxious and non-anxious adults with regard to the recollection of their upbringing (see for reviews Gerlsma et al. [13] and Rapee [14]). In these studies it was consistently demonstrated that greater anxiety is associated with more parental control (often referred to as 'overprotection') and less warmth (also referred to as 'more rejection'). The research of parenting and psychopathology through the recollection of adult patients was limited by its retrospective design, which could lead to distortions by faulty recall [13]. This has led to the recommendation to validate this line of work with an emphasis on cross-sectional or prospective designs $[15,16]$.

One way to study current parenting has been through the observation of parent-child interactions. Some studies investigated anxious children in non-clinical populations $[17,18]$, other studies focused on clinically anxious children [19-21]. Other ways to assess current parenting have been by either questioning parents directly about their childrearing attitudes and behaviours $[15,22]$ or questioning children in order to assess perceived parental rearing [23-25]. Overall, these studies on current parenting have largely corroborated the findings of retrospective studies, in demonstrating that parents of anxious children were more controlling or protective and/or more rejecting than parents of non-disordered children.

If a less warm and more controlling childrearing style serves as a mechanism for the transmission of anxiety disorders from parent to child, this style may be particularly prevalent among $\mathrm{AD}$ parents. This assumption has led to studies of the rearing style of $\mathrm{AD}$ parents [26-31].

Subjects of one study were AD mothers of infants. Parenting behaviour of 25 mothers with panic disorder (PD) and 24 normal controls toward their 4-month-old infants was assessed through observation at 4 months with a repetition at 8 months [30]. PD mothers were observed to display less sensitivity toward their 4 to 8 -month-old infants than controls. The parenting of 14-month-old infants by 27 mothers with PD and 18 controls was assessed through parental report, showing that PD mothers described more displays of anger toward their children than controls [30].

Four studies investigated AD parents of children in middle childhood [26, 27, 29, 31]. One of these studies also included mothers of preschoolers [26] and two also included parents of children in adolescence [27, 31]. In the first study, the rearing behaviour of 34 $\mathrm{AD}$ mothers and 36 mothers without AD (but in some cases with other psychiatric disorders) of 4 to 12-year-old children was assessed by observing the expressed emotion toward their offspring. Results showed that AD mothers directed more criticism toward their children than mothers with no history of $\mathrm{AD}$ [26]. In the second study, involving 
parents of 7 to 12-year-old children, parenting behaviours of $43 \mathrm{AD}$ parents (37 mothers) and 38 normal control parents (35 mothers) were assessed through a self-report questionnaire (Family Environment Scale; FES) [32], an interview measure (Parent Behaviour Interview; PBI) [33] and through a behavioural observation strategy, while the child was engaged in what might be considered 'risky' play. Anxious parents did not show more restrictive, cautious or critical behaviour toward their children. However, they reported higher levels of distress when their children engaged in 'risky' play. Furthermore, AD parents were less likely to express their feelings openly. The study suggested that parental affect, rather than parental behaviours, inhibits the child's activities [29]. The third study involved the taping and coding of three task situations in which 18 mothers (mostly panicdisordered) and 18 normal control mothers interacted with their children. The results showed that the parent-child interactions of AD mothers were characterized as less warm and positive, as less granting autonomy and as more critical and catastrophizing in comparison to the interactions of normal controls. In order to evaluate the contribution of maternal behaviours to the transmission of anxiety in families as well as the role of the child's anxiety in eliciting maternal behaviours, comparisons were made between anxious mothers with either anxious $(N=10)$ or non-anxious children $(N=8)$, and control mothers with non-anxious children $(N=16$; since only two non-anxious mothers had an anxious child, these two were excluded). Results suggested that maternal anxiety was the main contributor to (lower) maternal warmth. Maternal granting of autonomy was mainly predicted by child anxiety. Furthermore, it was found that maternal behaviours were more predictive of child anxiety than maternal psychopathology [27]. The same research group attempted to replicate these findings in a sample of 68 mother-child dyads (including 29 dyads in which both mother and child were anxiety-disordered, 15 dyads with AD mothers only, 8 dyads with AD children only, and 16 non-disordered dyads) [31]. The group's previous findings could be partially replicated, but in this study mothers of anxious children were found to be less warm regardless of their own anxiety level.

Despite differences in measures and methodology, most studies of the parenting style of AD parents show results similar to those found in the studies of parents of AD children mentioned earlier. When associations were found, they were found for both the 'warmth' dimension-with AD parents showing less warmth [27], more anger [30], and more criticism [26, 29] — and the 'control' dimension of parenting, with AD parents granting less autonomy [27]. Note, however, that all studies discussed until now have in common that they were completely [26, 27, 30, 31] or almost completely [29] restricted to mothers. This is remarkable, given the finding in studies of offspring of $\mathrm{AD}$ adults that the high risk of anxiety disorders in offspring is irrespective of the sex of the affected parent [34]. If parenting style is one of the mechanisms of transmission, it is important to investigate this in AD fathers as well. Furthermore these studies have in common that parenting style was either observed by outsiders or reported by the mother. Parenting style as perceived by the child was not studied, although it may be precisely the perceived rearing that contributes to the development of an anxiety disorder.

To our knowledge there is only one study that does not show these limitations [28]. This study examined the parents of a subsample of 816 fifteen-year-old children drawn from a longitudinal cohort of 7,775 children. This subsample was selected on the basis of previous self-reports of maternal depression. In this study these mothers were also screened for lifetime histories of diagnosable anxiety disorders (found in 148 cases), and current anxiety disorders (present in 57 cases). The fathers of the children in this subsample met criteria for a lifetime history of an anxiety disorder in 41 cases, whereas 24 had current anxiety disorders. Childrearing was assessed only through child report (Children's Report of 
Parental Behaviour Inventory; CRPBI) [35]. It was found that perceived maternal control predicted anxiety disorder in the child. However, maternal anxiety disorder (lifetime or current) failed to predict perceived parenting, and consequently a mediating role of parenting style in the transmission of anxiety disorders could not be established.

The present study further pursues questions raised in previous studies by investigating childrearing style in a population of clinically referred AD mothers and fathers (from separate families), using different perspectives: that of parent (self-) report and of child report. This allows us to address the following question: Do AD parents differ in their childrearing style (as reported by parent and child respectively) from non-disordered parents? If differences are found, we will explore whether these differences in childrearing (as reported by parent and child respectively) are found for both mothers and fathers with an anxiety disorder.

\section{Method}

\section{Participants}

Subjects were AD outpatients of a psychiatric outpatient clinic who were parents of schoolage children. Only AD patients with a comorbid psychotic disorder or comorbid substance abuse were excluded. Of the 60 patients who met the inclusion criteria, 39 AD outpatients were willing to participate, a $65 \%$ response rate. There were no differences in symptom severity between participants and non-participants. Of the 39 patients, three were excluded because of a total remission of their anxiety disorder. The definite sample consisted of 36 patients, 10 male with a mean age of 45 years (age range: 33-58), and 26 female with a mean age of 39 years (age range: 33-47); 31 AD parents were from two-parent families, 5 $\mathrm{AD}$ parents from single-parent families. $12 \mathrm{AD}$ parents reported about one child, and 24 AD parents about two children, a total of 60 children (35 girls and 25 boys), aged $6-18$ years $(M=12.0, \mathrm{SD}=3.3)$. Offspring from age 11 years and up filled out a parental rearing style questionnaire (EMBU-A) [36]. As a consequence, EMBU-A data were gathered in a subsample of the 36 families, i.e. 22 families.

The AD patients (as assessed by a structured clinical interview) had the diagnoses panic disorder with $(N=19)$ or without agoraphobia $(N=4)$, agoraphobia without panic disorder $(N=2)$, social phobia $(N=3)$, generalized anxiety disorder $(N=11)$, obsessive compulsive disorder $(N=5)$, posttraumatic stress disorder $(N=4)$ and simple phobia $(N=5)$. There was comorbidity among the anxiety disorders and with dysthymia $(N=11)$, and major depression $(N=3)$.

Fifty-nine control parents were recruited by means of a brochure distributed at schools situated in the catchment areas of the participating outpatient clinics. Presence of psychopathology (as assessed by a structured clinical interview), or a history of psychological or psychiatric help during parenthood was an exclusion criterion for participation in the control group; 22 parents were consequently excluded from the study. The final control group consisted of 36 parents (from separate families), i.e. 23 mothers and 13 fathers (32 were members of two-parent families; 4 were single parents). The ratio of mothers to fathers was similar to that in the clinical group. Fathers had a mean age of 45 years (age range: 41-50) and mothers a mean age of 43 years (age range: $36-51$ ). Five parents filled out self-reports on childrearing for only one child. Childrearing self-reports of the other 31 parents were completed for two children. The children (31 girls and 36 boys) were 
6-17 years of age $(M=11.8, \mathrm{SD}=2.9)$. As in the clinical sample, only offspring older than 10 years of age were asked to fill out a parental rearing style questionnaire (EMBU-A) [36]. As a consequence, EMBU-A data were gathered in a subsample of 24 families.

\section{Sociodemographic Variables}

All parents had Dutch nationality. All AD patients and 92\% $(N=33)$ of the non-clinical control parents were Caucasian. Family income represented a broad range with $18.3 \%$ falling in the lowest $20 \%$ of the Dutch population, $19.7 \%$ in the next $20 \%, 25.4 \%$ in the middle $20 \%$, and $18.3 \%$ in both the next and upper $20 \%$ of the Dutch population, according to Dutch Bureau of Census Norms.

\section{Measures}

\section{Psychiatric Assessment}

All participating parents were assessed by means of the Dutch version [37] of the Anxiety Disorders Interview Schedule-Revised (ADIS-R) [38]. The ADIS-R is a semi-structured diagnostic interview that was developed to facilitate reliable diagnosis of DSM-III-R anxiety disorders [39]. The interview also assesses mood disorders, and screens for Axis I bipolar and psychotic disorders. Research with the ADIS-R has yielded promising results for the reliability and validity of the interview [40].

The ADIS-R was scored by two independent raters. In cases of disagreement a senior clinical psychologist made the final decision. The raters were blind to the status of the respondent (clinical versus control). The interrater reliability was adequate, with Cohen's kappa of 0.94 for anxiety disorders and 0.87 for mood disorders.

\section{Childrearing Style-Parental Self-Report}

Parenting attitudes were assessed by means of the Child Rearing Practices Report (CRPR) [41, 42]. The CRPR assesses childrearing at the attitude level (rather than the actual behaviour level), which allows this instrument to be used for children ranging in age from pre-school (e.g., Hastings and Rubin) [43] to late adolescence (e.g., Gerhardt et al. [44]) In its original form the CRPR consists of 91 socialization statements in a Q-sort format. Factor analysis applied to the 91 items had found between 28 and 33 factors originally (hereafter called CRPR subscales) with good test-retest reliability [42] and construct validity $[45,46]$. In order to create more general and robust measures, this large number of factors has been factor-analytically reduced to two main scales: Nurturance and Restrictiveness [47].

Deković and colleagues [46] developed a questionnaire format of the CRPR, which was used in the present study. By means of a Dutch sample they have demonstrated that this questionnaire shows good reliability and construct validity of the factor-analytically derived childrearing scales Nurturance and Restrictiveness [46]. Nurturance expresses willingness of parents to share feelings and experiences with their children and to show affection, acceptance and responsiveness to the child's needs. Restrictiveness is characterized by a high degree of control, imposing narrow limits on the child's behaviour, and the endorsement of strict rules, requirements, and restrictions. 
Some of the original CRPR subscales [42] are conceptually important in the investigation of parental control in particular, but are not included in the main scales. For exploratory reasons we therefore included the following original CRPR subscales alongside the main factors Nurturance and Restriction: Negative Affect Toward Child (Cronbach's alpha $=0.61$ ), Worry About the Child (Cronbach's alpha $=0.55$ ), and Encouraging Independence (Cronbach's alpha $=0.62$ ). The CRPR questionnaire used in this study consists of 52 items, with a 6-point Likert-type scale. In this study parents filled out a separate CRPR questionnaire for each child.

\section{Childrearing Style-Child Report}

The EMBU [48] is a self-report questionnaire, originally developed in Sweden and translated into Dutch, to assess adults' memories of their childrearing, with regard to mothers and fathers separately [49]. It has been widely used in samples of various origins and across various cultures [13, 50]. Gerlsma developed an adolescent version of the EMBU (i.e., EMBU-A) to assess current childrearing style as experienced by children aged 11 years and up, which has proven to be reliable and construct valid [36]. The factor structure found in adults could be confirmed in adolescents, i.e. the factors Rejection, Emotional Warmth, Overprotection and Favouring Subject [36]. The 81-item questionnaire has a four-point forced-choice scale. In the present study, children from 11 years of age and older filled out the EMBU-A with regard to the participating parent.

\section{Procedure}

The study was approved by the institutional review board of the Leiden University Medical Centre and the Valeriuskliniek. From April 1996 to October 1997, AD patients with children aged 6-18 were approached through the four participating outpatient anxiety clinics, which they (the parents) had turned to for help.

After permission had been obtained, the parental questionnaires were mailed prior to the appointment with the parents of both samples, together with the informed consent form. For the non-disordered control group the ADIS-R was administered during the visit with the parent (patients had been interviewed with the ADIS-R during the assessment at the clinic). All children aged 11 years and up were visited at home by one of the interviewers for the purpose of administering the EMBU-A. During the interview the parents were not present and it was emphasized that the child's answers would be treated confidentially.

\section{Statistical Analysis}

One patient in the AD group was considered an outlier, since the answers given, although in the expected direction, were more extreme ( $Z$-scores for several variables, $Z>3$ ). Although the severity of the psychopathology was in the same range as that of the other patients in the AD sample, language problems due to an Eastern European background may have been responsible for the tendency to give extreme answers. To preclude a possible artificially reinforcing effect on the results, this case was excluded from the clinical sample. The definite clinical group therefore consisted of 35 parents.

In line with research on multiple-informants and childrearing [51, 52], we aggregated ratings in an attempt to assess the childrearing style of each parent with greater validity. When reports on parenting were available for two children in the same family, the mean of 
the scores was used in the data analysis. Since our study focused on determining differences in childrearing between parents with and without an anxiety-disorder, within-family differences were not taken into consideration.

Differences between AD and control parents in self-reported childrearing (CRPR) and child reported childrearing (EMBU-A) were examined using a $2 \times 2$ factorial analysis of variance, with group ( $\mathrm{AD}$ versus control) and gender of the parent as factors. Differences in parent reported childrearing style were investigated for the two main scales of the CRPR. In addition, differences in parent reported childrearing style were examined at a more detailed level, using three of the original subscales of the CRPR. Differences in child reported childrearing style were examined for the four scales of the EMBU-A. The Holm modified Bonferroni correction [53] was applied to evaluate the significance of the data. Holm has suggested a modified Bonferroni method that adequately maintains experimentwise error rates at the desired alpha level but that is more powerful than the traditional Bonferroni-based approach [53].

\section{Results}

To ensure that our results on childrearing were not confounded with other variables, we compared the sample of AD parents and the non-disordered control sample on the following variables: child age and gender; number of children in the family; one- or twoparent family; family income. The two groups did not differ on these variables. In addition, we evaluated the relationship between these variables and the dependent variables. If significant correlations were found (age children-Encouraging Independence, $r=0.42$, $p<0.001$; number of children-Worry about the Child, $r=-0.35, p<0.01$; family income-Negative Affect Towards Child, $r=-0.35, p<0.01)$, these variables were covaried in the analysis of the corresponding dependent variable to control for any confounds. However, the inclusion of these variables as covariates did not have a significant impact on any of the results, indicating that differences between $\mathrm{AD}$ and control parents were not explainable by differences in these variables.

\section{Parent Reported Childrearing Style}

$\mathrm{AD}$ and control parents differed significantly in self-reported rearing behaviour on the two main CRPR factors Nurturance and Restrictiveness (see Table 1). AD parents reported a less nurturing and more restrictive rearing style than control parents.

When rearing style was investigated at the CRPR subscale level, the following results were found: $\mathrm{AD}$ parents reported more negative affect towards their children, less granting of independence, and more worry about their children.

For Nurturance and, on a subscale level, Worry About the Child a significant gender effect was found, $F(67,1)=6.27, p<0.02$ and $F(67,1)=4.89, p<0.03$ respectively. Mothers reported that they reared their children in a more nurturing way $(M=96.1)$ and that they worried more about their children $(M=6.7)$ than fathers reported $(M=92.4$ and $M=5.4$ respectively).

With regard to the two main CRPR scales and the additional CRPR subscales, no interaction effects between group and gender of the parent were found. This indicates that the differences between fathers and mothers are comparable (i.e., not significantly different) for both $\mathrm{AD}$ parents and control parents. In other words, the differences found 
Table 1 Mean parent reported childrearing scores on CRPR (standard deviation): comparison of AD and Normal Control Parents

\begin{tabular}{|c|c|c|c|c|c|c|c|}
\hline \multirow[t]{2}{*}{ CRPR } & \multicolumn{3}{|l|}{ AD parents } & \multicolumn{3}{|c|}{ Normal Control parents } & \multirow[t]{2}{*}{$F$-ratio for group } \\
\hline & $\begin{array}{l}\text { Mothers } \\
(N=25)\end{array}$ & $\begin{array}{l}\text { Fathers } \\
(N=10)\end{array}$ & $\begin{array}{l}\text { Total } \\
(N=35)\end{array}$ & $\begin{array}{l}\text { Mothers } \\
(N=23)\end{array}$ & $\begin{array}{l}\text { Fathers } \\
(N=13)\end{array}$ & $\begin{array}{l}\text { Total } \\
(N=36)\end{array}$ & \\
\hline \multicolumn{8}{|l|}{ Main factors } \\
\hline Nurturance & $93.9(5.8)$ & $89.9(6.3)$ & $92.8(6.1)$ & $98.5(6.1)$ & $94.4(7.8)$ & $97.0(6.9)$ & $7.7 * *$ \\
\hline $\begin{array}{l}\text { Restrictiveness } \\
\text { Subscales }\end{array}$ & $62.0(13.5)$ & $63.1(7.9)$ & $62.3(12.1)$ & $52.3(14.3)$ & $55.1(11.0)$ & $53.3(13.1)$ & $7.3 * *$ \\
\hline Negative affect & $7.2(3.0)$ & $7.7(2.7)$ & $7.3(2.9)$ & $5.6(2.4)$ & $5.3(2.3)$ & $5.5(2.3)$ & $8.7 * *$ \\
\hline $\begin{array}{l}\text { Worry about } \\
\text { the child }\end{array}$ & $7.4(2.1)$ & $6.9(2.5)$ & $7.2(2.2)$ & $6.0(1.9)$ & $4.2(2.1)$ & $5.4(2.1)$ & $13.9 * * *$ \\
\hline $\begin{array}{l}\text { Encouraging } \\
\text { independence }\end{array}$ & $29.3(4.0)$ & $27.8(4.3)$ & $28.9(4.1)$ & $31.5(4.6)$ & $31.3(4.1)$ & $31.4(4.4)$ & $6.8 * *$ \\
\hline
\end{tabular}

$* * p<0.01 ; * * * p<0.001$

between families with an $\mathrm{AD}$ parent and control families are relevant for both $\mathrm{AD}$ mothers and $\mathrm{AD}$ fathers.

\section{Child Reported Childrearing Style}

In contrast to their AD parents, the children did not report more Rejection or less Emotional Warmth through the EMBU-A than children of control parents (see Table 2). However, children of AD parents did report significantly more overprotection than children of control parents.

Children of $\mathrm{AD}$ parents did not perceive more parental favouring than children of controls. No interaction effects were found between group and gender, indicating that differences in overprotection between families with an AD parent and control families are relevant for both $\mathrm{AD}$ mothers and $\mathrm{AD}$ fathers.

To explore associations between parent and child measures of childrearing, Pearson product-moment correlations between CRPR scales and EMBU-A scales were computed across groups (using one-tailed tests as the expected direction was known). Parental report of Negative Affect Towards Child was related to child's perception of Rejection $(0.29$, $p<0.05)$ and parental perception of Worry About the Child to child report of Overprotection $(0.58, p<0.001)$. A trend was found for the correlation between parent reported Nurturance and child report of Emotional Warmth $(0.24, p<0.06)$. All three correlations were in the expected direction.

Table 2 Mean child reported childrearing scores on EMBU-A (standard deviation): comparison of AD families and Normal Control families

\begin{tabular}{|c|c|c|c|c|c|c|c|}
\hline \multirow[t]{2}{*}{ EMBU-A } & \multicolumn{3}{|l|}{ AD families } & \multicolumn{3}{|c|}{ Normal Control families } & \multirow[t]{2}{*}{$F$-Ratio for group } \\
\hline & $\begin{array}{l}\text { Mothers } \\
(N=15)\end{array}$ & $\begin{array}{l}\text { Fathers } \\
(N=7)\end{array}$ & $\begin{array}{l}\text { Total } \\
(N=22)\end{array}$ & $\begin{array}{l}\text { Mothers } \\
(N=16)\end{array}$ & $\begin{array}{l}\text { Fathers } \\
(N=8)\end{array}$ & $\begin{array}{l}\text { Total } \\
(N=24)\end{array}$ & \\
\hline Rejection & $24.3(3.7)$ & $23.1(2.7)$ & $23.9(3.4)$ & $23.2(4.0)$ & $22.1(1.9)$ & $22.8(3.4)$ & 0.95 \\
\hline Emotional warmth & $63.5(10.1)$ & $67.0(4.6)$ & $64.7(8.8)$ & $65.0(6.6)$ & $60.5(10.2)$ & $63.5(8.0)$ & 0.90 \\
\hline Overprotection & $22.9(4.6)$ & $22.1(4.6)$ & $22.7(4.5)$ & $20.9(3.7)$ & $18.9(3.5)$ & $20.2(3.7)$ & $4.07 *$ \\
\hline Favouring subject & $7.4(2.2)$ & $6.7(1.3)$ & $7.1(1.9)$ & $7.2(1.7)$ & $6.4(1.4)$ & $6.9(1.6)$ & 0.21 \\
\hline
\end{tabular}

$* p<0.05$ 


\section{Discussion}

The rearing style of AD parents differed from that of non-disordered controls. AD parents judged their childrearing style as less warm (nurturant) and more controlling (restrictive). Interestingly, this pattern corresponds with that reported retrospectively by $\mathrm{AD}$ patients about their parents, and with findings on current parenting as reported by anxious children in non-clinical samples. The convergence of these findings is suggestive for the role childrearing plays in the transgenerational transmission of anxiety disorders.

With respect to the first main finding, i.e. AD parents describing a less warm childrearing style (i.e., Nurturance) compared to non-disordered control parents, AD parents also reported at CRPR subscale level higher Negative Affect Towards Child when compared to controls. This is akin to the finding of both Hirshfeld and colleagues [26] and Whaley and colleagues [27] of a higher level of criticism in AD mothers toward their children.

The children of $\mathrm{AD}$ parents did not differ from controls in perceived Rejection and perceived Emotional Warmth. In studies of parenting, findings based on parent report and those based on child report often diverge [51, 54, 55]. This discrepancy may reflect differences in perspective and cognitive abilities. A difference in perspective also appears from the moderate correspondence between parental perception of Nurturance and Negative Affect Towards Child and the child's perception of Emotional Warmth and Rejection. However, the small sample size of children reporting on childrearing style might also account for the differences in findings on parent report and child report.

The cross-sectional nature of the study precludes judgement about the causal direction of the findings on nurturance and on negative affect of the parent towards the children. It is conceivable that those $\mathrm{AD}$ parents who are inclined to a rearing pattern of relatively lower nurturance and/or relatively higher negative affect facilitate the development of an anxiety disorder in their child. When parents are low on acceptance, warmth and responsiveness, the child is more liable to develop an insecure attachment relationship - a risk factor for the development of psychopathology in general, including anxiety disorders [56]. However, because children of AD parents are more often genetically predetermined to higher anxiety and behavioural inhibition [57], we cannot rule out the possibility that the child's temperament or anxiety disorder evokes negative affect in the AD mother (a geneenvironment interaction) [58].

The second main finding is a more controlling (restrictive) style of rearing by AD parents, according to parental self-report. The subscales of the CRPR allow us a closer look at some components that constitute overprotective behaviour, showing AD parents reporting to encourage independence significantly less and to worry about their children significantly more than control parents. With regard to this aspect we find convergence between parents and children, as the children of $\mathrm{AD}$ parents reported significantly more overprotection. The correlation between parent reported Worry About the Child and the child's perception of Overprotection, underlines this convergence. We should point out here that the EMBU-A Overprotection scale encompasses a wide range of aspects (e.g., fear and anxiety for the child's safety, guilt engendering, intrusiveness, overinvolvement) $[36,59]$.

Parental control reduces opportunities for the child to develop new skills and to explore and manipulate the environment. This parenting style diminishes a sense of control in the child, and thereby fosters anxiety $[16,58]$. But again we should also consider the possibility of a gene-environment interaction. Recent findings support the hypothesis that child characteristics elicit this type of rearing behaviour [27, 31]. A child with an anxious, 
behaviourally inhibited temperament may easily impress the parent as more vulnerable, and thereby evoke firmer parental control. In a model of the development of (generalized) anxiety disorder, Rapee [58] suggested that rather than a characteristic of the parent, overprotective parenting is a characteristic of the parent-child interaction: parents respond to their child's vulnerability with excessive control and protection, and in turn augment this vulnerability.

Having discussed the role of childrearing style in the transmission of anxiety across generations it is good to keep in mind that there are other ways in which anxious parents may contribute to the development of fear in children as well, notably by the modelling of anxious behaviours [60], and by providing negative information about certain stimuli and situations, instilling in the child expectancies which more likely will produce a fear reaction $[61,62]$.

The differences in rearing style between AD parents and control parents applied to both $\mathrm{AD}$ mothers and $\mathrm{AD}$ fathers, whether assessed through parent self-report or child report. Obviously, this finding needs to be replicated in larger samples, but it is important to keep in mind that the earlier discussion of the role of parental warmth and parental control in the development of $\mathrm{AD}$ pertains to fathers as much as to mothers.

That no gender effect was found in the way $\mathrm{AD}$ parents differ from controls, does not mean that mothers and fathers in general show a similar rearing style. Based on selfreports, our study showed mothers to be more nurturing than fathers, in the group of AD parents as well as in the group of control parents. This finding is in accordance with many other studies on gender differences in childrearing style (for a review see Gerlsma et al. [63]).

Some limitations of our study which we readily acknowledge include the relatively small sample size, and the fairly wide age range of children (6-18 years). Although in our analyses we controlled for effects of child's age and gender, the sample size did not allow us to look for differential effects of these factors. Child's age seems to have played a minor role in the present findings, as it was not significantly correlated with aspects of childrearing style, with the exception of parent reported Encouraging Independence. Gender of the child did not correlate significantly with rearing variables. Obviously studies with larger samples are needed to test the generalizability of these findings. Furthermore, the high level of comorbidity among the anxiety disorders and with affective disorders in our sample precluded the analysis of specific associations between type of anxiety disorder (with or without comorbid depression) and childrearing style. It may well be that suffering from one anxiety disorder (e.g. social phobia) has a different impact on parenting behaviour than being affected with another (e.g. panic disorder). Until now this is an unexplored area in the research of childrearing style of AD parents, which requires studies with larger samples.

Another point worth mentioning is the role of treatment. At the start of the present study almost all patients were already in treatment. Although parenting practices were not formally addressed, it is possible that some patients applied insights from their personal therapy (e.g. the importance of active coping, rather than avoiding) to their parental behaviour. If this did occur, it may have weakened our results, where differences between $\mathrm{AD}$ parents and normal controls would have been more pronounced before treatment.

Three more suggestions can be made for future research. The sample consisted of AD parents only and it remains to be seen whether the differences found are specific for AD parents, or are rather a characteristic of parents with psychopathology in general. Secondly, incorporating data on anxiety disorders in the offspring would enable further investigation of the mediating role of childrearing style in the association between 
parental AD and child AD. Thirdly, as in other studies of parental rearing in high-risk samples, childrearing is approached in this study as the rearing style of an individual parent. Although this is the usual way to approach the data collected in studies of highrisk samples, we believe this is also an important limitation. In the majority of families a parent brings up a child together with a co-parent.

The present study adds to previous research on the role of parenting in anxiety disorders, since we have investigated current parenting rather than retrospective recall, in a population of AD parents, and have done so from two perspectives: the parent's and the child's. We were able to demonstrate that AD parents differ from non-disordered parents in their perceived childrearing style. By including both male and female AD patients, we were also able to show that gender does not play an important role in the differences found in childrearing.

Through an exploratory analysis (by including subscales) we were able to shed new light on different aspects of control that are typical of AD parents. Further research along this line will enable us to trade the rather imprecise label 'overprotective' for more precise descriptions of control provided by anxious parents.

Our findings point to a possible mechanism in the transmission of anxiety disorders within families, although obviously research in longitudinal samples will be necessary to show whether the childrearing style typical of $\mathrm{AD}$ parents contributes to the emergence of an anxiety disorder in their child. Knowledge about the childrearing style typical of AD parents will be of clinical importance in adult psychiatric care as well as in child and adolescent psychiatry. It may clarify the potential role of parenting in the transmission of anxiety disorders and may offer concrete possibilities for intervention.

\section{Summary}

Anxiety disorders run in families. Heredity provides only a partial explanation for this aggregation. It has been suggested that childrearing style contributes as well. Retrospective studies have shown that a less warm and more controlling rearing style is reported by AD patients. If this childrearing style serves as a mechanism for the transmission of anxiety disorders, we would expect it to be more prevalent in AD parents.

The present study investigated childrearing style in a population of AD parents from two perspectives, parent (self-) report and child (self-) report, and included both AD mothers and AD fathers. Results demonstrated that AD parents reported a more controlling and less warm rearing style in comparison to non-disordered control parents. Children of AD parents reported being overprotected more than children of non-disordered parents; they did not report differences in perceived parental warmth. Differences found applied to both $\mathrm{AD}$ mothers and $\mathrm{AD}$ fathers. The results may explain the non-genetic transmission of anxiety disorders from one generation to the next. However, gene-environment interactions, i.e. parental reactions to characteristics of the child, need to be considered as well.

Acknowledgements Thanks are due to T. Rombouts, and other staff members of the psychiatric clinics, and the participating patients and their families. Prof. Dr. Ph.D.A. Treffers has contributed valuable comments to this paper. We gratefully acknowledge the assistance of Y. van Wankum and clinical psychology graduate students in conducting this investigation. Completion of this study was facilitated by Grant 4105 from the Dutch National Fund for Mental Health. 


\section{References}

1. Weissman MM, Leckman JF, Merikangas KR, Gammon GD, Prusoff BA (1984) Depression and anxiety disorders in parents and children: results from the Yale Family Study. Arch Gen Psychiatry 41:845-852

2. Turner SM, Beidel DC, Costello A (1987) Psychopathology in the offspring of anxiety disorders patients. J Consult Clin Psychol 55:229-235

3. Mancini C, van Ameringen M, Szatmari P, Fugere C, Boyle M (1996) A high-risk pilot study of the children of adults with social phobia. J Am Acad Child Adolesc Psychiatry 35:1511-1517

4. Biederman J, Faraone SV, Hirshfeld-Becker DR, Friedman D, Robin JA, Rosenbaum JF (2001) Patterns of psychopathology and dysfunction in high-risk children of parents with panic disorder and major depression. Am J Psychiatry 158:49-57

5. Kashani JH, Vaidya AF, Soltys SM, Dandoy AC, Katz LM, Reid JC (1990) Correlates of anxiety in psychiatrically hospitalized children and their parents. Am J Psychiatry 147:319-323

6. Last CG, Hersen M, Kazdin A, Orvaschel H, Perrin S (1991) Anxiety disorders in children and their families. Arch Gen Psychiatry 48:928-934

7. Kendler KS, Heath AC, Martin NG, Eaves LJ (1987) Symptoms of anxiety, symptoms of depression. Same genes, different environments? Arch Gen Psychiatry 44:451-457

8. Eaves LJ, Silberg JL, Meyer LM, Maes HH, Simonoff E, Pickels A, Rutter M, Neale MC, Reynolds CA, Erickson MT, Heath AC, Loeber R, Truett KR, Hewitt JK (1997) Genetics and developmental psychopathology: 2. The main effects of genes and environment on behavioral problems in the Virginia Twin Study of Adolescent Behavioral Development. J Child Psychol Psychiatry 38:965-980

9. Van der Valk JC, Verhulst FC, Neale MC, Boomsma DI (1998) Longitudinal genetic analysis of problem behaviors in biologically related and unrelated adoptees. Behav Genet 28:365-380

10. Boer F, Lindhout IE (2001) Family and genetic influences: is anxiety " all in the family"'? In: Silverman WK, Treffers PhDA (eds) Anxiety disorders in children and adolescents: research, assessment and intervention. Cambridge University Press, Cambridge, pp 235-254

11. Perris C (1994) Linking the experience of dysfunctional parental rearing with manifest psychopathology: a theoretical framework. In: Perris C, Arrindell WA, Eisemann M (eds) Parenting and psychopathology. John Wiley \& Sons, Chichester, pp 3-32

12. Treffers PhDA, Silverman WK (2001) Anxiety and its disorders in children and adolescents before the twentieth century. In: Silverman WK, Treffers PhDA (eds) Anxiety disorders in children and adolescents. Research, assessment and intervention. Cambridge University Press, Cambridge, pp 1-22

13. Gerlsma C, Emmelkamp PMG, Arrindell WA (1990) Anxiety, depression, and perception of early parenting: a meta-analysis. Clin Psychol Rev 10:251-277

14. Rapee RM (1997) Potential role of childrearing practices in the development of anxiety and depression. Clin Psychol Rev 17:47-67

15. Messer SC, Beidel DC (1994) Psychosocial correlates of childhood anxiety disorders. J Am Acad Child Adolesc Psychiatry 33:975-983

16. Chorpita BF, Barlow DH (1998) The development of anxiety: the role of control in the early environment. Psychol Bull 124:3-21

17. Hock M, Krohne HW (1989) Mütterliches Erziehungsverhalten während einer Hausaufgabenanfertigung und Angstlichkeit beim Kind. Zeitschrift fur Pädagogische Psychologie, 2:169-180

18. Krohne HW, Hock M (1991) Relationship between restrictive mother-child interactions and anxiety of the child. Anxiety Res 4:109-124

19. Dadds MR, Barrett PM, Rapee RM, Ryan S (1996) Family process and child anxiety and aggression: an observational analysis. J Abnorm Child Psychol 24:715-734

20. Siqueland L, Kendall PC, Steinberg L (1996) Anxiety in children: perceived family environments and observed family interaction. J Clin Child Psychol 25:225-237

21. Hudson JL, Rapee RM (2001) Parent-child interactions and anxiety disorders: an observational study. Behav Res Ther 39:1411-1427

22. Bowen F, Vitaro F, Kerr M, Pelletier D (1995) Childhood internalizing problems: prediction from kindergarten, effects of maternal overprotectiveness, and sex differences. Dev Psychopathol 7:481-498

23. Muris P, Merckelbach H (1998) Perceived parental rearing behavior and anxiety disorders symptoms in normal children. Pers Individ Dif 25:1199-1206

24. Grüner K, Muris P, Merkelbach H (1999) The relationship between anxious rearing behaviors and anxiety disorders symptomatology in normal children. J Behav Ther Exp Psychiatry 30:27-35

25. Lieb R, Wittchen H, Höfler M, Fuetsch M, Stein MB, Merikangas KR (2000) Parental psychopathology, parenting styles, and the risk of social phobia in offspring. Arch Gen Psychiatry 57:859-866 
26. Hirshfeld DR, Biederman J, Brody L, Faraone SV, Rosenbaum JF (1997) Expressed emotion toward children with behavioral inhibition: associations with maternal anxiety disorder. J Am Acad Child Adolesc Psychiatry 36:910-917

27. Whaley SE, Pinto A, Sigman M (1999) Characterizing interactions between anxious mothers and their children. J Consult Clin Psychol 67:826-836

28. McClure EB, Brennan PA, Hammen C, Le Brocque RM (2001) Parental anxiety disorders, child anxiety disorders, and the perceived parent-child relationship in an Australian high-risk sample. J Abnorm Child Psychol 29:1-10

29. Turner SM, Beidel DC, Roberson-Nay R, Tervo K (2003) Parenting behaviors in parents with anxiety disorders. Behav Res Ther 41:541-554

30. Warren SL, Gunnar MR, Kagan J, Anders TE, Simmens SJ, Rones M, Wease S, Aron E, Dahl RE, Sroufe LA (2003) Maternal panic disorder: infant temperament, neurophysiology, and parenting behaviors. J Am Acad Child Adolesc Psychiatry 42:814-825

31. Moore PS, Whaley SE, Sigman M (2004) Interactions between mothers and children: impacts of maternal and child anxiety. J Abnorm Psychol 113:471-476

32. Moos RH, Moos BS (1986) Family Environment Scale Manual. 2nd edn. Consulting Psychologists Press, Palo Alto, CA

33. Parker G, Tupling H, Brown LB (1979) A Parental Bonding Instrument. Br J Med Psychol 52:1-10

34. Dierker LC, Merikangas KR, Szatmari P (1999) Influence of parental concordance for psychiatric disorder on psychopathology in offspring. J Am Acad Child Adolesc Psychiatry 38:280-288

35. Schludermann S, Schludermann E (1988) Shortened Child Report of Parent Behavior Inventory (CRPBI-30): Schludermann Revision. Unpublished manuscript. University of Manitoba, Winnipeg, Canada

36. Gerlsma C, Arrindell WA, van der Veen N, Emmelkamp PMG (1991) A parental rearing style questionnaire for use with adolescents: a psychometric evaluation of the EMBU-A. Pers Individ Dif 12:1245-1253

37. De Ruiter C, Bouman TK, Hoogduin CAL (1993) Anxiety Disorders Interview Schedule-Dutch version

38. Di Nardo PA, Barlow DH (1988) Anxiety Disorders Interview Schedule-Revised (ADIS-R). Phobic and Anxiety Disorders Clinic, State University of New York, Albany, NY

39. Di Nardo PA, Moras K, Barlow DA, Rapee RM, Brown TA (1993) Reliability of DSM-III-R anxiety disorder categories. Using the Anxiety Disorders Interview Schedule-Revised (ADIS-R). Arch Gen Psychiatry 50:251-256

40. De Ruiter C (1994). Het Anxiety Disorders Interview Schedule-Nederlandse versie (1993). Gedragstherapie 1:65-68

41. Block JH (1965) The Child-Rearing Practices Report. Institute of Human Development, University of California, Berkeley, CA

42. Block JH (1981) The Child-Rearing Practices Report (CRPR): a set of Q items for the description of parental socialisation attitudes and values. Unpublished manuscript. Berkeley, CA: Institute of Human Development, University of California

43. Hastings PD, Rubin KH (1999) Predicting mothers' beliefs about preschool-aged children's social behavior: evidence for maternal attitudes moderating child effects. Child Dev 70(3):722-741

44. Gerhardt CA, Vannatta K, McKellop JM, Tayler J, Passo M, Reiter-Purtill J, Zeller M, Noll RB (2003) Brief report: child-rearing practices of caregivers with and without a child with juvenile rheumatoid arthritis: perspectives of caregivers and professionals. J Pediatric Psychol 28(4):275-279

45. Kochanska G, Kuczynski L, Radke-Yarrow M (1989) Correspondence between mother's self-reported and observed child-rearing practices. Child Dev 60:56-63

46. Deković M, Janssens JMAM, Gerris JM (1991) Factor structure and construct validity of the Block Child Rearing Practices Report (CRPR). Psychol Assess: J Consult Clin Psychol 3:182-187

47. Rickel AV, Biasatti LL (1982) Modifications of the Block Child Rearing Practices Report. J Clin Psychol 38:129-134

48. Perris C, Jacobsson L, Lindström H, von Knorring L, Perris H (1980) Development of a new inventory of parental rearing behavior. Acta Psychiatr Scand 61:265-274

49. Arrindell WA, Emmelkamp PMG, Brilman E, Monsma A (1983) Psychometric evaluation of an inventory for assessment of parental rearing practices: a Dutch form of the EMBU. Acta Psychiatr Scand 67:163-177

50. Arrindell WA, Perris C, Eisemann M, Van der Ende, Gaszner P, Iwawaki S, Maj M, Zhang J-E (1994) Parental rearing behavior from a cross-cultural perspective : A summary of data obtained in 14 nations. In: Perris C, Arrindell WA, Eisemann M (eds) Parenting and psychopathology. John Wiley \& Sons Ltd, Chichester, pp 145-171 
51. Schwarz JC, Barton-Henry ML, Pruzynski T (1985) Assessing child-rearing behaviors: a comparison of ratings made by mother, father, child, and sibling on the CRPBI. Child Dev 56:462-479

52. Bögels SM, Oosten A van, Muris P, Smulders D (2001) Familial correlates of social anxiety in children and adolescents. Behav Res Ther 39:273-287

53. Holm S (1979) A simple sequentially rejective multiple test procedure. Scand J Stat 6:65-70

54. Gerlsma C, Snijders TAB, van Duijn MAJ, Emmelkamp PMG (1993) It's a family affair, or is it? Differences in family members' perceptions of parental rearing styles, In: Gerlsma C, (ed) Parental rearing styles and psychopathology: memories of parenting revisited, dissertation, Enschede

55. Gonzales NA, Cauce AM, Mason CA (1996) Interobserver agreement in the assessment of parental behavior and parent-adolescent conflict: African-American mothers, daughter, and independent observers. Child Dev 67:1483-1498

56. Manassis K (2000) Childhood anxiety disorders: lessons from the literature. Can J Psychiatry 45:724730

57. Biederman J, Rosenbaum JF, Hirshfeld DR, Faraone SV, Bolduc EA, Gersten M, Meminger SR, Kagan J, Snidman N, Reznick JS (1990) Psychiatric correlates of behavioral inhibition in young children of parents with and without psychiatric disorders. Arch Gen Psychiatry 47:21-26

58. Rapee RM (2001) The development of generalized anxiety. In: Vasey MW, Dadds MR (eds) The developmental psychopathology of anxiety. Oxford University Press, New York, pp 481-503

59. Markus MTh, Lindhout IE, Boer F, Hoogendijk THG, Arrindell WA (2003) Factors of perceived parental rearing styles: the EMBU-C examined in a sample of Dutch primary school children. Pers Individ Dif 34:503-519

60. Gerull FC, Rapee RM (2002) Mother knows best: effects of maternal modelling on the acquisition of fear and avoidance in toddlers. Behav Res Ther 40:279-287

61. Field AP, Argyris NG, Knowles KA (2001) Who's afraid of the big bad wolf: a prospective paradigm to test Rachman's indirect pathways in children. Behav Res Ther 39:1259-1276

62. Muris P, Bodden D, Merckelbach H, Ollendick TH, King N (2003) Fear of the beast: a prospective study on the effects of negative information on childhood fear. Behav Res Ther 41:195-208

63. Gerlsma C, Emmelkamp PMG (1994) How large are gender differences in perceived parental rearing styles?: a meta-analytic review. In: Perris C, Arrindell WA, Eisemann M (eds) Parenting and psychopathology. John Wiley \& Sons, Chichester, pp 55-73 